\title{
Video-intuboscopic assistance is a useful aid to tracheal intubation in pediatric patients
}

\author{
[L'assistance vidéoscopique facilite l'intubation endotrachéale des patients \\ pédiatriques]
}

Markus Weiss, ${ }^{*} \dagger$ Kirsten Hartmann, ${ }^{*}$ Joachim Fischer, $†$ Andreas C. Gerber*

Purpose: To evaluate the efficacy of video-intuboscopic assisted tracheal intubation in a difficult intubation setting.

Methods: In 50 pediatric patients (mean age $12.8 \pm 3.1$ yr, range $6-16$ yr) a grade 3 direct laryngoscopic view was simulated. Eight certified registered nurse anesthetists without experience in endoscopic intubation performed tracheal intubation on five or more patients using the video-optical intubation stylet. Time from insertion of the tube into the oral cavity until the tip had passed the vocal cords was recorded. Failed intubation was defined as intubation $>60 \mathrm{sec}$, arterial oxygen saturation $<92 \%$ or esophageal intubation. Subjective degree of difficulty was asked from the operators using a Likert-scale.

Results: Forty-six of the 50 patients were successfully intubated within $60 \mathrm{sec}$ and without arterial oxygen desaturation. In four patients, video-assisted tracheal intubation failed due to prolonged intubation time. Intubation times ranged from 10-40 sec (median $15 \mathrm{sec})$. Mean intubation time in the first patient $(24.5 \pm 17.3 \mathrm{sec})$ appeared longer than for the fifth patient $(20.8 \pm 10.9 \mathrm{sec})$, but the difference was not statistically significant $(P=0.87)$. Mean estimated degree of difficulty was $3.9 \pm 2.1$. Subjective estimates of difficulty increased with intubation times $(P=0.00 \mathrm{I})$.

Conclusion: The video-optical intubation stylet can be considered a valuable aid for tracheal intubation in pediatric patients with a difficult airway.

Objectif : Évaluer l'efficacité de l'intubation endotrachéale assistée par vidéoscope dans le contexte d'une intubation difficile.

Méthode : Une vision laryngoscopique directe de grade 3 a été simulée chez 50 patients pédiatriques (âge moyen : 12,8 \pm 3, I ans, limites de 6-16 ans). Huit infirmières anesthésistes qualifiées, mais sans expérience en intubation endoscopique, ont réalisé l'intubation endotrachéale de cinq patients ou plus en utilisant le stylet d'intubation vidéo-optique. L'intervalle compris entre l'insertion de la sonde dans la bouche et le moment où la pointe a dépassé les cordes vocales a été noté. L'échec a été défini comme une intubation $>60 \mathrm{~s}$, une saturation du sang artériel en oxygène $<92 \%$ ou une intubation œsophagienne. Les opérateurs ont estimé le degré de difficulté subjective selon une échelle de Likert.

Résultats : Des 50 intubations, 46 ont été réussies en moins de 60 $s$ et sans désaturation du sang artériel en oxygène. Chez quatre patients, l'intubation endotrachéale vidéoscopique a échoué à cause d'un temps d'intubation prolongé. Les temps d'intubation vont de 10-40 s (médiane de $15 \mathrm{~s}$ ). Le temps moyen d'intubation du premier patient (24,5 $\pm 17,3 \mathrm{~s})$ a été plus long que celui du cinquième $(20,8$ $\pm 10,9 \mathrm{~s})$, mais la différence n'était pas statistiquement significative $(P=0,87)$. Le degré moyen de difficulté a été de 3,9 $\pm 2,1$. La difficulté d'intubation a été subjectivement estimée plus grande avec le temps d'intubation $(P=0,001)$.

Conclusion : On peut donc considérer le stylet d'intubation vidéooptique comme un accessoire valable à l'intubation endotrachéale chez les patients pédiatriques dont l'intubation est difficile.

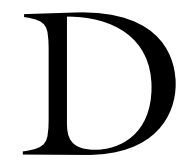

IFFICULT tracheal intubation is an important cause of anesthesia related morbidity and mortality. ${ }^{1,2}$ Unfortunately, no single factor reliably predicts these difficulties. $^{3-5}$ Several techniques and devices are recommended for the management of unanticipated difficult intubation. ${ }^{6-8}$ In such situations, many anesthesiologists rely on simple intubation aids such as a gum elastic bougie or a conventional malleable intubation stylet. ${ }^{9,10}$

From the Departments of Anaesthesia* and Intensive Care and Neonatology, $†$ University Children’s Hospital, Zurich, Switzerland. Address Correspondence to : Dr. Markus Weiss, Department of Anaesthesia, University Children's Hospital, Steinwiesstrase 75, Zurich, Switzerland. Phone: +41 l 26671 11; Fax +41 1266 71 68; E-mail: markus.weiss@kispi.unizh.ch

Disclosure statement: Dr. Weiss is the inventor of the presented video-optical intubation stylet but does not maintain any patent rights. Dr. Weiss serves on the Medical Board of Acutronic Medical Systems AG to promote the further development of video-assisted intubation techniques and the related equipment.

Accepted for publication March 13, 2001.

Revision accepted April 4, 2001. 
This technique, however, can result in failed or esophageal intubation. Moreover, blind probing for the glottic opening increases the risk of airway trauma, bleeding and swelling. The latter increase the difficulty of subsequent fibre-optic intubation and may render ventilation via the face mask more difficult or even impossible. ${ }^{11,12}$

Recently, we reported on the use of a video-endoscopic system within the tracheal tube for supervising tracheal intubation in pediatric patients. ${ }^{13}$ The videodisplay allowed the supervisor to instantly recognize malpositioned endotracheal tubes (ETT). It also provided a simple and rapid assistance to endoscopic intubation during impaired direct laryngoscopic view of the cords.

The aim of the present study was to evaluate systematically the efficacy of video-intuboscopic assisted tracheal intubation using a malleable video-optical intubation stylet (VOIS) in a setting simulating difficult intubating conditions.

\section{Methods}

With hospital Ethical Committee approval 50 ASA I-II pediatric surgical patients, from six to $16 \mathrm{yr}$, requiring orotracheal intubation were enrolled into this study. No patient was undergoing emergency surgery and no tracheal intubation required rapid sequence induction. Premedication and induction of anesthesia (inhalational or iv) depended upon the requirements and preferences of the patient. Before induction of anesthesia, the VOIS was lubricated and inserted into a cuffed ETT, not protruding the tube tip. The VOIS was locked with a sliding connector to the ETT adapter preventing rotational and longitudinal displacement (Figure 1). An antifog agent was applied to the lens tip using a sterile gauze. The viewfinder is attached to a conventional video-endoscope camera and the standard Storz light adapter is connected to a light source by means of a light cable.

Before induction of anesthesia, the VOIS was bent to a "hockey stick" shape and was checked for proper function and adequate monitor view. Routine monitoring, including precordial stethoscope, pulse oximetry, electrocardiography, non-invasive blood pressure monitoring were established. After adequate mask ventilation was achieved, a non-depolarizing muscle relaxant was administered and inspiratory oxygen concentration increased to $100 \%$. The patient's head positioned in the sniffing position, initial conventional laryngoscopy was performed by the intubator as usual. The best direct laryngoscopic view obtained was classified according to Cormack and Lehane. ${ }^{14}$ Then, the operator lowered the laryngoscope to an extent such

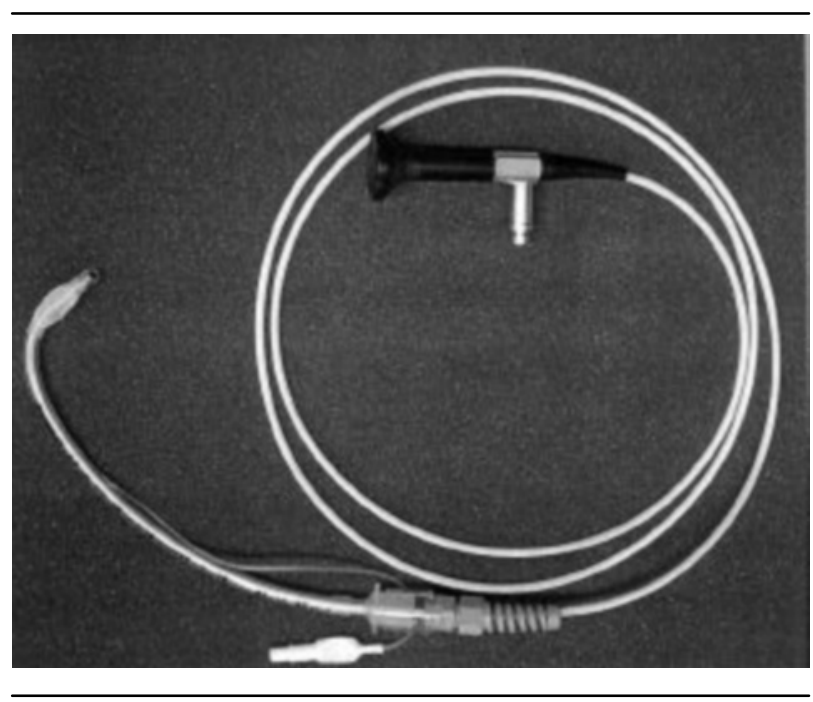

FIGURE I Malleable video-optical intubation stylet (VOIS) consisting of a flexible fibreoptic endoscope $(2 \mathrm{~m}$ long, $3.8 \mathrm{~mm}$ in diameter, viewing angle $50^{\circ}$ ) and a distally integrated $30 \mathrm{~cm}$ long malleable forming element (Acutronic Medical Systems, AG, Hirzel, Switzerland). The endoscope carries optic fibres for image transmission (10'000 pixels) and light fibres for airway illumination. The sliding connector is used to lock the endoscope to the ETT adapter preventing rotational and longitudinal displacement. The videostylet intubation stylet can be used with ETTs with internal diameter of $5 \mathrm{~mm}$ and larger. The viewfinder is attached to a conventional video-endoscope camera and the standard Storz light adapter is connected to a light source by means of a light cable.

that the epiglottis descended, and provided a grade 3 view which was confirmed by the investigator. Subsequently, the ETT tip was placed about $1 \mathrm{~cm}$ above the epiglottis under direct vision. While watching the monitor view from the stylet tip, the ETT was then guided around the epiglottis, through the glottis and into the trachea (Figure 2). After passing the vocal cords, the VOIS was transiently drawn back, before advancing the ETT further down the trachea. Finally, tracheal ETT position was confirmed or adjusted by means of the monitor display. After removing the VOIS from the ETT, correct placement was confirmed by auscultation and capnography.

All intubations were performed by eight nurse anesthetists with varying experience in direct laryngoscopy (mean $8.1 \pm 7.9 \mathrm{yr}$; range $1.5-25 \mathrm{yr}$ ), who had received brief instructions prior to the study. Each nurse performed tracheal intubation on five or more patients.

The time requirement from insertion of the ETT into the oral cavity until the tube tip had passed the vocal cords, as indicated on the video-monitor, was recorded. Failed intubation was defined as intubation 


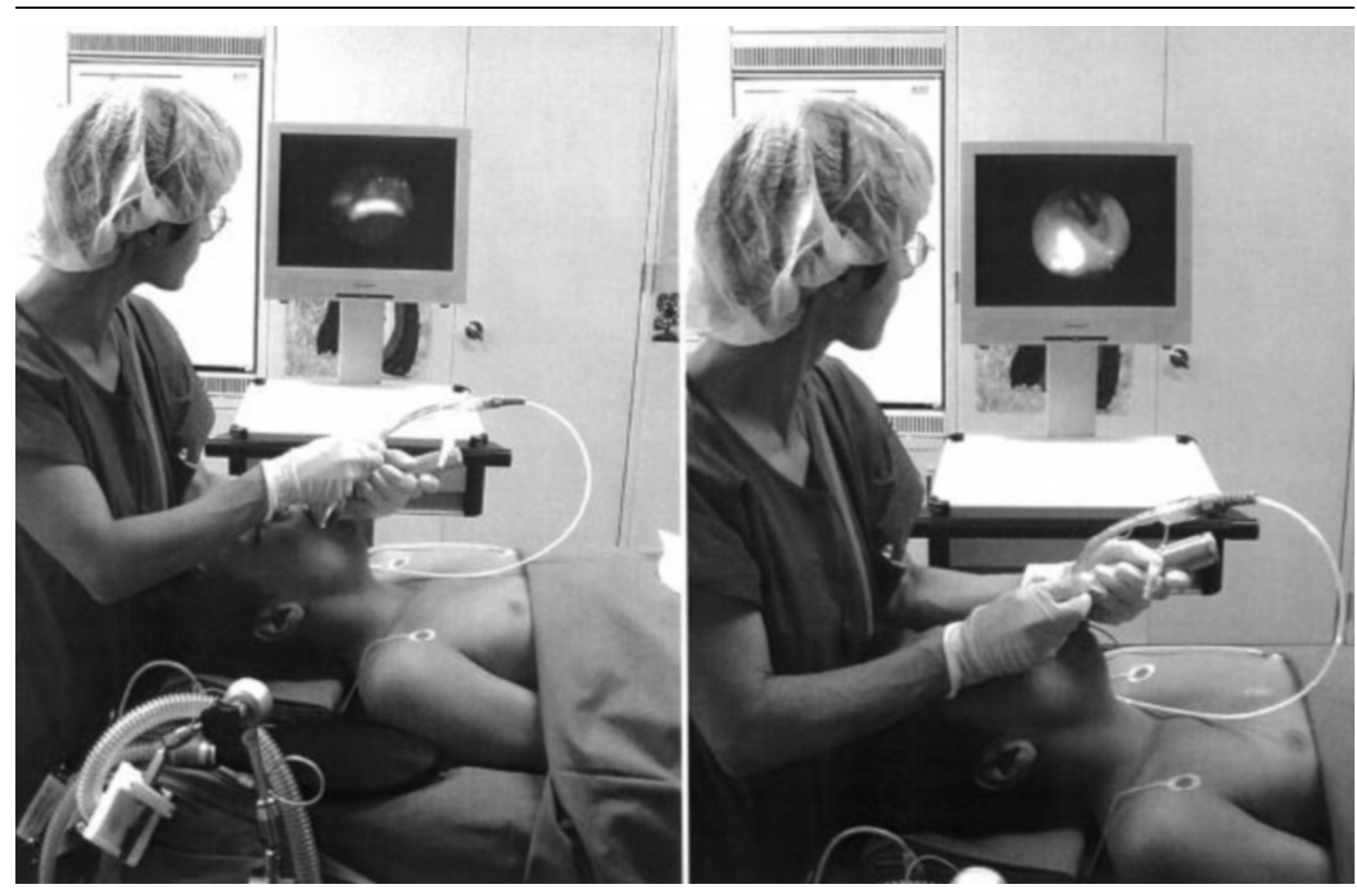

FIGURE 2 Video-assisted tracheal intubation in simulated grade 3 laryngoscopy using the video-optical intubation stylet. After placing the ETT with it's angled tip above the epiglottis, the epiglottis is visualized on the video-monitor (left) and subsequently the ETT tip is guided behind the epiglottis through the vocal cords under visual control (right).

time exceeding $60 \mathrm{sec}$ (potentially leading to hypoxemia in the insufficiently pre-oxygenated patient or critically ill patient with limited respiratory reserves), esophageal intubation or if arterial oxygen saturation fell below 92\% during intubation. Visibility of the subglottic airway anatomy after passing the cords and of the tracheal carina on the monitor was recorded. Difficulties with, and attributed to, the fibre-optic stylet during intubation were recorded. After completing the procedure, participants had to estimate the subjective degree of difficulty with regard to intubation on a ten-point Likert-scale ranging from l (=very simple) to 10 (=very difficult).

We evaluated, by means of Cox proportional hazard analysis, whether any of the following variables was associated with the time required for successful intubation: experience of the intubating nurse anesthetist in direct laryngoscopy (in years), estimated difficulty, sequence of intubation attempt; patient gender, age, weight or length and best direct laryngo- scopic view. Simple regression analysis was conducted to explore associations between estimated difficulty and any of the aforementioned variables. A significance level of $P<0.05$ was employed.

Results

Fifty pediatric patients (mean age $12.8 \pm 3.1 \mathrm{yr}$ ) were enrolled in the study. Tracheal intubation with the VOIS was successful in 46 children. In four patients, video-intuboscopic assisted tracheal intubation failed due to intubation time $>60 \mathrm{sec}$. These occurred in two intubators during the first three intubation attempts. Intubation times ranged from $10-40 \mathrm{sec}$ (median 15 sec). On average, mean intubation time in the first patient $(24.5 \pm 17.3 \mathrm{sec})$ appeared to be longer than in the fifth patient $(20.8 \pm 10.9 \mathrm{sec})$, but the difference was not statistically significant $(P=0.87)$. Two patients, in whom direct laryngoscopy revealed a genuine grade 3 laryngoscopic view, were also successfully intubated within 33 and $13 \mathrm{sec}$, respectively. Cox 
regression analysis revealed a strong positive association between subjectively perceived difficulty and increased intubation times (Wald chi-square $=25.4, P$ $<0.0001$ ) and a less pronounced association between experience and shorter intubation times (Wald chisquare $=12.3, P=0.0004)$. None of the other variables was associated with time to successful intubation.

Although the glottic opening was visualized very rapidly in all patients, insertion of the tube into the trachea was delayed by compromised saggital manoeuvring within the hypopharynx (requiring manual adjusting of the angled ETT tip) and due to the narrow airway in children.

While subglottic airway structures were visible in all successful intubations, visualisation of the tracheal carina was achieved only in 26 patients (52\%) because of the angled tip and small viewing angle of the scope.

Mean estimated degree of difficulty was $3.9 \pm 2.1$ (median 3). Again, estimated degree of difficulty was strongly associated with intubation time $(P=0.001$, the latter explaining $76 \%$ of the observed variance in estimated difficulty). Experience in laryngoscopy and number of attempts retained a weak, but significant association.

No problems were reported in relation to the ETT being connected to the bedside monitoring system by way of an endoscopic cable or to the removal of the intubation stylet from the ETT. Fogging of the distal lens occurred in six patients, but the view was still sufficient to conduct the intubation procedure. In two patients improper initial placement of the ETT tip into the vallecula resulted in soiling of the lens by secretions and required subsequent cleaning.

\section{Discussion}

The purpose of this study was to evaluate the efficacy of video-intuboscopic assisted tracheal intubation by nurse anesthetists in a clinical setting reproducing difficult intubating conditions. The main finding is, that tracheal intubation was successful in $92 \%$ of all patients using the VOIS for a simulated grade 3 view of the larynx.

If difficulties with intubation are expected, the use of sophisticated approaches such as fibre-optic intubation in the awake or carefully sedated patient can be performed with skilled assistance and extensive preparation. However, difficulties with intubation are not always predictable and not all anesthesiologists are familiar with the bronchoscopic technique. In the emergency situation, fibre-optic intubation is likely to take too long, especially in inexperienced hands.

The video-assisted intubation technique combines the advantages of guiding the intubation stylet during conventional laryngoscopy and of fibre-optic endotracheal intubation.

Our results demonstrate that nurse anesthetists, representing operators not experienced with bronchoscopic intubation, were able to intubate the trachea in a grade 3 situation using the view obtained from the tip of the ETT. The ease of video-assisted intubation was reflected by the high success rate and rapidity of intubation after only a few attempts, and the low subjective degree of difficulty. These results confirm our earlier data obtained in mannequin studies. ${ }^{15,16}$ The technique, if performed strictly and exactly as described, may be considered a useful alternative for managing unexpected difficult laryngoscopy.

Because the endoscopic intubation technique does not jeopardize patient safety, it can be taught daily, during conventional laryngoscopy, allowing the anesthesiologist to be prepared for patients with unexpected difficult laryngoscopy. The device, not containing steering mechanics or a suction channel, is less expensive approximately (2000 US\$) and more robust, and therefore less susceptible to damage during handling, cleaning and preparing, than a regular (more sophisticated) fibre-optic bronchoscope.

If the VOIS is inserted into the ETT before starting anesthesia (standby mode), it can be used immediately without modification of the intubation procedure and without additional assistance, when endoscopic intubation is required. This can be useful for intubation with a rapid induction sequence or in patients with limited cardio-respiratory function. If not used for intubation, the VOIS at least may help to confirm tracheal tube position before it is removed from the ETT. Possibly, the technique may be also useful for patients in whom head-neck extension and cardiovascular response to forced laryngoscopy should be avoided.

The VOIS presented does not contain a port for suctioning or administering oxygen during tracheal intubation. This increases the susceptibility to problems inherent to fibre-optic scopes in general, such as fogging of the lens or interference with secretions and blood. A further limitation is the reduced manoeuvrability of the ETT tip due to the limited oro-pharyngeal space. This problem can be, partially, overcome by insertion and steering of the ETT from the angle of the mouth. Second, ETT insertion through the cords was affected by the narrow airway of children. This implies that a protruding stylet would be helpful to enter the glottis first, with subsequent passage of the ETT over the stylet. However, this requires a less traumatic and more flexible stylet to avoid airway trauma.

Recently, different fibre-optic stylets with viewfinders were developed to give a view from the tip of the 
ETT to a proximal viewfinder to facilitate difficult tracheal intubation. ${ }^{17,18}$ These can be used without external light sources and video-camera systems, and therefore are considered to be superior to video-optical equipped devices. ${ }^{18}$ However, in our opinion, videotransmission of the endoscopic view facilitates the endoscopic procedure, improves manual dexterity and allows nearly simultaneous observation of the video-display, patient and monitors in a comfortable and efficient position for intubation. The use of a miniature screen video system, as recently presented by Popat, considerably improves feasibility. ${ }^{19}$ Gravenstein et al. reported on a similar video-enhanced optical intubation stylet, but preferred to avoid direct laryngoscopy and to grasp the mandible and elevate the jaw and tongue during tracheal intubation. ${ }^{20}$

To use optical stylets alone without the use of a laryngoscope may reduce the potential hemodynamic changes and the morbidity associated with direct laryngoscopy. ${ }^{21,22}$ However, the presented video-intuboscopic intubation technique is not a primary endoscopic intubation technique but an option to aid conventional tracheal intubation when unexpected difficulties with direct laryngoscopy arise. In addition, the use of the VOIS with conventional laryngoscopy remains a familiar procedure, maintains the airway open, and reduces the risk of contamination of the distal lens by blood or secretions. ${ }^{20,23}$

Some caveats with regard to this study must be considered. We evaluated the technique in a simulated difficult intubation setting. Although it is an accepted model for testing, comparing and teaching intubation techniques, further experience with genuine grade 3 and 4 laryngoscopic view is required to confirm our preliminary results. Second, the study was performed in children, rarely presenting intubation difficulties in experienced hands. On the other hand, the limited manoeuvrability of the stylet and the smaller airways in children may increase the validity of the simulation model tested. Further studies would benefit from evaluating the presented technique in regard to complications such as trauma, bleeding or sore throat, particularly in comparison with other techniques such as tracheal intubation with the lighted stylet or tracheal intubation through the intubating laryngeal mask.

In conclusion, our preliminary clinical experience in children suggests that video-intuboscopic assisted tracheal intubation is a valuable and simple aid for intubation in the presence of unpredicted difficult laryngoscopy. Little training, even for anesthesiologists without experience in endoscopic intubation techniques, is required.

\section{References}

1 Caplan RA, Posner KL, Ward FW, Cheney FW. Adverse respiratory events in anesthesia: a closed claims analysis. Anesthesiology 1990; 72: 828-33.

2 Cheney FW. The American Society of Anesthesiologists closed claims project. What have we learned, how has it affected practice, and how will it affect practice in the future? Anesthesiology 1999; 91: 552-6.

3 Randell T. Prediction of difficult intubation. Acta Anaesthesiol Scand 1996; 40: 1016-23.

4 Karkouti K, Rose DK, Wigglesworth D, Cohen MM. Predicting difficult intubation: a multivariable analysis. Can J Anesth 2000; 47: 730-9.

5 Tse JC, Rimm EB, Hussain A. Predicting difficult endotracheal intubation in surgical patients scheduled for general anesthesia: a prospective blind study. Anesth Analg 1995; 81: 254-8.

6 Caplan RA, Benumof JL, Berry FA, et al. Practice guidelines for management of the difficult airway. A report by the American Society of Anesthesiologists Task Force on management of the difficult airway. Anesthesiology 1993; 78: 597-602.

7 Crosby ET, Cooper RM, Douglas MJ, et al. The unanticipated difficult airway with recommendations for management. Can J Anaesth 1998; 45: 757-76.

8 Reed AP. The unanticipated difficult airway. Anesthesiology Clinics of North America 1996; 14: 443-53.

9 Kidd JF, Dyson A, Latto IP. Successful difficult intubation. Use of the gum elastic bougie. Anaesthesia 1988; 43: 437-8.

10 Gataure PS, Vaughan RS, Latto IP. Simulated difficult intubation. Comparison of the gum elastic bougie and the stylet. Anaesthesia 1996; 51: 935-8.

11 Domino KB, Posner KL, Caplan RA, Cheney FW. Airway injury during anesthesia. A closed claims analysis. Anesthesiology 1999; 91: 1703-11.

12 Kadry M, Popat M. Pharyngeal wall perforation - an unusual complication of blind intubation with a gum elastic bougie. Anaesthesia 1999; 54: 404-5.

13 Weiss M, Schwarz U, Dillier CM, Gerber AC. Videointuboscopic monitoring of tracheal intubation in pediatric patients. Can J Anesth 2000; 47: 1202-6.

14 Cormack RS, Lehane J. Difficult tracheal intubation in obstetrics. Anaesthesia 1984; 39: 1105-11.

15 Weiss M, Schwarz U, Gerber AC. Difficult airway management: comparison of the Bullard laryngoscope with the video-optical intubation stylet. Can J Anesth 2000; 47: 280-4.

16 Biro P, Weiss M, Gerber A, Pasch T. Comparison of a new video-optical intubation stylet versus the conventional malleable stylet in simulated difficult tracheal intubation. Anaesthesia 2000; 55: 886-9. 
17 Kitamura T, Yamada $\Upsilon$, Du HL, Hanaoka K.

Efficiency of a new fibreoptic stylet scope in tracheal intubation. Anesthesiology 1999: 91: 1628-32.

18 Saruki N, Saito S, Sato J, Kon N, Tozawa R. Swift conversion from laryngoscopic to fiberoptic intubation with a new, handy fiberoptic stylet. Anesth Analg 1999; 89: 526-8.

19 Popat MT, Howells. Miniature screen for fibreoptic intubation using a camera (Letter). Anaesthesia 1997; 52: 802-3.

20 Gravenstein D, Melker RJ, Lampotang S. Clinical assessment of a plastic optical fiber stylet for human tracheal intubation. Anesthesiology 1999; 91: 648-53.

21 Kitamura T, Yamada $\Upsilon$, Du HL, Hanoka K. An efficient technique for tracheal intubation using the styletscope alone. Anesthesiology 2000; 92: 1210-1.

22 Kitamura T, Yamada $\Upsilon$, Chinzei M, Du HL, Hanaoka $K$. Attenuation of haemodynamic responses to tracheal intubation by the styletscope. Br J Anaesth 2001; 86: 275-7.

23 Couture P, Perreault C, Girard D. Fibreoptic bronchoscopic intubation after induction of general anaesthesia: another approach (Letter). Can J Anaesth 1992; 39: 99.

24 Goldberg JS, Bernard AC, Marks RJ, Sladen RN.

Simulation technique for difficult intubation: teaching tool or new hazard? J Clin Anesth 1990; 2: 21-6. 